\title{
Direção - Visões da Procura
}

A experiência de compor a equipe de direção dos 958m do nosso Bom Retiro foi marcante em muitos aspectos, sobretudo no que diz respeito ao nível de entrega exigido, às experimentações relacionadas ao espaço urbano, ao trabalho detalhado de planejamento de ensaios e o modo pelo qual o diálogo com os espectadores retroalimentou nossa atuação no campo da encenação. A partir dessa vivência, tento apontar abaixo algumas considerações iniciais, sobre o meu percurso nesse processo.

0-200m - Em geral nossos ensaios tinham uma estrutura que se mantinha: a primeira etapa, com os atores, iniciava às $19 \mathrm{~h}$ e seguia com toda a equipe até as 23h30. Em seguida, sentados em círculo no Teatro Taib ou no shopping Lombroso, discutíamos alguns pontos com os responsáveis pelas áreas de iluminação, direção de arte, som, produção e figurino. A terceira etapa da noite era a reunião da equipe de direção para avaliação e planejamento do dia seguinte. Isso significava, em média, um árduo trabalho até por volta de umas 05h da manhã. Chamava-me a atenção a capacidade do Antônio Araújo, ou Tó, como costuma ser chamado, em tensionar esse diálogo de modo a estimular que cada criador(a) envolvido chegasse a novas proposições artísticas, técnicas e às vezes metodológicas. Um diálogo construído numa zona de escuta, exigência e provocação da qual era difícil sair sem ter o chão das certezas ou das zonas de segurança abalados. Acredito que essa perspectiva do "não está resolvido ainda" colocava a todos num eterno processo de "procura". Ali, naquela roda entre biscoitos para aliviar o cansaço, algumas reflexões me alimentavam: entre as certezas e as incertezas, onde encontramos mais potência para criar? Por que parece que buscamos sempre o caminho mais difícil para fazer algo? Enquanto o modo de produção vigente parece entoar a lei do fazer mais, com menos e em menos tempo,

\footnotetext{
${ }^{1}$ Francis Willker de Carvalho É diretor do Teatro do Concreto, mestrando do programa de pós-graduação da ECAUSP e assistente de direção do espetáculo Bom Retiro, 958 metros.
} 
ter que resolver tudo rapidamente, colecionar respostas e estratégias que escalonam nosso grau de competência e eficácia...ali, na vertigem da criação, resistia o espaço para encontrar a resposta que ainda não estava pronta e o tempo para longas e calorosas discussões que se pautavam pelo compromisso com o exercício da criação, aquela tentativa de dar forma ao universo de afetos que o material criado mantinha em estado de potência e que nos atravessava. Já as sextas-feiras eram religiosamente dedicadas ao "passadão", momento em que, a partir da sequência definida pelo roteiro, as cenas eram apresentadas sem interrupção. Estratégia que permitia ver a forma que o trabalho estava ganhando, testar - na cena - espaços, transições, luz, som, objetos, movimentos, possibilidades interpretativas dos atores... Percebo que esse procedimento contribuía também para que o espetáculo fosse ganhando e mantendo um ritmo no seu percurso, ao passo que revelava conquistas e desafios em todas as áreas. Na segunda-feira, era comum a primeira hora ser dedicada a uma avaliação geral, na qual todos os envolvidos apontavam suas impressões, críticas, sugestões a partir daquilo que tinham percebido no "passadão" realizado. O ritmo dos ensaios se intensificaria quando da proximidade da estreia, entrando madrugada adentro e povoando as ruas desertas do Bom Retiro com o jogo vivo entre os atores.

200-458m - A relação com os diferentes espaços que compõem o espetáculo se deu, sobretudo na fase final de desenho da encenação, a partir de quatro movimentos que às vezes ocorrem de modo mais simultâneo e, em outros casos, alternadamente: o primeiro diz respeito ao que poderíamos chamar de levantar as cenas nos espaços propostos e perceber como essa composição se mostrava; o segundo envolve um estudo mais minucioso do espaço e as perspectivas de jogo que ele possibilita; o terceiro movimento tem como foco a própria visibilidade da cena na sua relação com os espectadores, e, a partir dessa perspectiva, muitas cenas acabam sendo reestruturadas para que os espectadores tenham maior visibilidade. Exemplo disso foi a incorporação de uma escada para a cena da faxineira limpando o espelho do shopping. Por último, durante os ensaios abertos essa relação com o espaço pode ainda sofrer alterações de duas naturezas: às vezes requer uma mudança mesmo de espaço e, em outros casos, envolve pensar o modo como conduzir o público para/por aquele espaço. Exemplo disso é a cena em frente à loja Lot, onde assistimos um diálogo entre a Costureira e a Rádio Infinita. A personagem da Faxineira conduz parte dos espectadores até passarem dessa loja, e, nesse momento, pede para a parte que está em 
frente à vitrine se afaste para o fundo do corredor e convida aqueles espectadores que tinham passado para retornarem à frente da loja e sentarem no chão, de modo que todos possam ver a cena. Esse movimento lembra um recuo de bateria como ocorre no carnaval.

Numa outra perspectiva, a relação com o espaço urbano em cenas como o desfile de moda (Rua José Paulino), a briga (Rua Ribeiro de Lima) e o momento de caos proposto na Rua Correia de Melo levaram em conta desde a observação atenta do trânsito que se estabelecia nessas regiões nos dias e horários em que trabalhávamos e também aspectos mais subjetivos relacionados à percepção que tínhamos dessas ruas, que sentimentos elas nos lembravam. Exemplo disso é o pequeno trecho entre a José Paulino e a Ribeiro de Lima onde encenamos a cena em que o Abandonado descarta as duas manequins: durante os ensaios nos deparávamos com aquela paisagem sempre muito solitária, escura, ressaltando uma sensação de vazio e solidão. Lili (Eliana Monteiro) apelidou esse trecho de "Rua das Perdas" e é justamente nele que as possíveis promessas feitas pelo Abandonado às duas manequins se desfazem, perdem-se, assim como o vínculo afetivo dele com elas. Essas cenas que ocorrem nas ruas e seus respectivos cruzamentos foram criadas e amadurecidas nos próprios espaços onde hoje ocorrem. Isso significou no trabalho com os atores exercícios que pudessem mobilizar sua visão periférica e agilidade para lidar com o trânsito, além da própria familiaridade que iriam construindo com esses fluxos para estabelecer o jogo com eles. Entendemos que muitas são as possibilidades de jogo com o espaço urbano. Para alguns artistas se trata de uma composição urbana ${ }^{2}$, para outros, de intervenção urbana ou ainda teatro de invasão ${ }^{3}$. Cada conceito gera um modo relacional com esse espaço. Nas discussões com o Tó, o desejo era estabelecer um jogo com o espaço urbano que conseguisse fazer conviver no mesmo fluxo o real e a ficção proposta pelo espetáculo. Desse modo, o princípio a ser praticado não era o de obstruir ou interromper o trânsito, por exemplo, mas ao contrário: nossa procura era por jogar com esse trânsito, correr com ele numa mesma "veia/via". Esse foi o convite feito aos atores e também um desafio que exigiu muitas experimentações. No caso da cena do desfile, por exemplo, quais gestos e ações poderiam ser utilizados, quando necessário, para propor diálogos com os motoristas/carros que desfilam com

\footnotetext{
2 Termo utilizado pelo grupo Corpos Informáticos, de Brasília, DF.

${ }^{3}$ Termo utilizado pelo diretor e pesquisador André Carreira.
} 
os atores? Acredito que foi o incessante fazer, o fato de lidar com a situação concreta a cada ensaio que permitiu aos atores jogarem, numa situação que envolve o risco, de modo mais seguro. Há ainda outra dimensão nessa relação com o espaço, que é intencional - a sua carga semântica. A escolha da Rua José Paulino para a cena do desfile não foi aleatória, pois ela inscreve um texto múltiplo para pensar o bairro, sobretudo se levarmos em conta que os atores desfilam sob tapetes bolivianos grudados na rua, que é símbolo do comércio de vestuário em São Paulo.

458-778m - No planejamento dos ensaios, discutíamos na equipe de direção cada cena e as questões trazidas pelos atores e atrizes, assim como os aspectos onde se concentravam os maiores desafios em termos de configuração do desenho da cena e também de atuação ou dramaturgia. A partir disso criávamos um mapa de trabalho, com os nortes desejados para cada cena e nos dividíamos (Tó, Lili, Antônio Duran e eu), de modo que simultaneamente muitas delas eram trabalhadas. Em alguns momentos desse processo foi necessário retomar visitas para que os atores pudessem ampliar seu repertório de referências. Isso significou voltar à Cracolândia, observar os consumidores durante o dia na Rua José Paulino, assistir vídeos de desfile de moda para identificação de gestual etc. Nesse percurso com os atores, o trabalho da coreógrafa e diretora Renata Melo e da atriz e professora Isabel Setti foi importante contribuição tanto para a pesquisa de movimento quanto para as possibilidades vocais para materializar as situações e intenções propostas pelo texto. Nesse trecho do caminho, a ideia de "procura" também era constante para nós e para os atores, pois não havia respostas prontas: tínhamos nortes que eram buscados num trabalho conjunto, bastante aberto às proposições dos atores também. Lembro-me de discussões com os atores sobre as características de cada coro, que mapa de ações seria correspondente e mesmo de exercícios individuais com eles na busca de uma individualização de cada um que integrava os diferentes coros. Mais uma vez a "busca" incessante fazia com que mesmo diante da proximidade da estreia alguns atores e atrizes ainda apresentassem workshops e propostas após o horário do ensaio. Foi numa dessas proposições que a atriz Káthia Bissoli apresentou sua "manequim-viva" e que a partir do olhar do Tó teve suas aparições ampliadas ao longo do percurso, configurando-se também como um forte eixo dramatúrgico dentro do espetáculo. Ela aparece cinco vezes e a cada nova aparição o índice promoção/desconto vai aumentando (30\%,60\% ...) até chegar no final da peça jogada numa caçamba, nua, violentada, com a placa de $100 \%$. Vejo 
nesse exemplo mais uma vez reafirmado esse caráter de um processo permanentemente em trânsito, aberto e propositivo.

778-958m - A relação com o espectador durante o processo de criação do espetáculo foi um ponto que me marcou muito nesse processo. Esse diálogo se estabeleceu durante ensaios abertos anteriores à estreia e mesmo depois da estréia. Observar o processo de escuta do Tó foi para mim um aprendizado bastante significativo. Para ele, toda opinião tem importância e eu podia perceber a mobilização do seu próprio corpo nesse exercício de se interessar e levar em consideração o ponto de vista do outro. Esse retorno do público se deu de diferentes modos: conversas após um ensaio ou apresentação, em e-mails recebidos por Tó ou por alguém do grupo, comentários orais trazidos por alguém da equipe, além da rica contribuição da pesquisadora Beth Néspoli que, ao entrevistar espectadores para sua pesquisa de doutorado, também nos alimentava de instigantes questões. Lembro-me que, em dado momento, boa parte de nossa reunião de direção era dedicada a ler e ouvir os diferentes comentários reunidos e pensar sobre eles, discuti-los à exaustão, de modo a considerá-los ou refutá-los, de modo bastante consciente e coerente com aquilo que nos guiava na criação do Bom Retiro 958m. Um exemplo dessa etapa é a cena do musical de cracômanos que acontece no palco do Taib. A partir desses retornos, verificamos que para muitos espectadores a incisão crítica que desejávamos com a cena não se configurava. Essa constatação fez com que o Tó propusesse uma quebra de quarta parede em determinado momento da coreografia e que os atores se desfizessem de seus cobertores e personagens para apenas olhar, em silêncio, os espectadores por um breve momento. Essa quebra da espetacularidade parece ter contribuído para evidenciar/explicitar a conotação crítica e política que buscávamos.

Creio que o relato acima consegue apontar algumas considerações iniciais sobre as questões que afetaram a direção/encenação no processo de criação de Bom Retiro, especialmente do meu ponto de vista. Desembarcar nessa equipe me proporcionou um rico espaço de troca criativa, de pensar metodologias e procedimentos de trabalho, de aprender com tantos profissionais diferentes. Rememorar esse trajeto acorda muitas lembranças que poderiam gerar abordagens múltiplas diante do processo. Porém, tentei apresentar aqui aquelas que me afetaram de modo mais contundente até o momento. Poderia ser interessante explicitar a relação com as demais áreas de criação, como notei seus percursos e a interface com esses profis- 
sionais ou até aprofundar nas questões que envolveram o meu trabalho muito próximo de Renata Melo e dos atores. Contudo, há um limite de tempo e espaço que preciso respeitar e, de todo modo, Bom Retiro 958m está vivo na temporada prorrogada até dezembro e tenho tido a oportunidade de seguir acompanhando suas apresentações, espaço privilegiado para lidar com novas perguntas e reflexões que podem ser desdobradas posteriormente. Para mim esse processo ou a minha relação com ele poderia ser sintetizado na ideia de trânsito, de uma obra em permanente movimento. Bom Retiro é bem ali....onde a procura nunca cessa! 